\title{
The influence of the land surface on the transition from dry to wet season in Amazonia
}

\author{
R. Fu and W. Li \\ With 8 Figures \\ Received November 29, 2002; revised July 21, 2003; accepted July 30, 2003 \\ Published online April 20, 2004 (C) Springer-Verlag 2004
}

\begin{abstract}
Summary
Analysis of the fifteen years of European Centre for Medium Range Weather Forecasts (ECMWF) reanalysis suggests that the transition from dry to wet season in Southern Amazonia is initially driven by increases of surface latent heat flux. These fluxes rapidly reduce Convective Inhibition Energy (CINE) and increase Convective Available Potential Energy (CAPE), consequently providing favourable conditions for increased rainfall even before the large-scale circulation has changed. The increase of rainfall presumably initiates the reversal of the crossequatorial flow, leading to large-scale net moisture convergence over Southern Amazonia. An analysis of early and late wet season onsets on an interannual scale shows that a longer dry season with lower rainfall reduces surface latent heat flux in the dry and earlier transition periods compared to that of a normal wet season onset. These conditions result in a higher CINE and a lower CAPE, causing a delay in the increase of local rainfall in the initiating phase of the transition and consequently in the wet season onset. Conversely, a wetter dry season leads to a higher surface latent heat flux and weaker CINE, providing a necessary condition for an earlier increase of local rainfall and an earlier wet season onset. Our results imply that if land use change in Amazonia reduces rainfall during dry and transition seasons, it could significantly delay the wet season onset and prolong the dry season.
\end{abstract}

\section{Introduction}

The importance of the water cycle to the ecosystem of Amazonia, especially that of the rainfor- est, has been clearly demonstrated by many previous studies (e.g. Salati and Vose, 1984; Nepstad et al., 2002). However, the relative role of land surface water fluxes and moisture transport from the Atlantic Ocean in maintaining the current precipitation climatology remains unclear. Such an understanding is needed to determine whether the continuing land use change in Amazonia may cause the climate to reach a threshold, beyond which further changes to the land surface will shift the precipitation regime significantly enough to threaten the remaining rainforest, as well as agriculture in the adjacent regions.

The Large-Scale Biosphere-Atmosphere Experiment in Amazonia (LBA) has provided unprecedented observations of the land surface biosphere and atmosphere over Amazonia. However, such observations alone cannot entirely address the fundamental LBA question of whether "land surface changes will shift the precipitation regime?", because moisture transport from the Atlantic and external oceanic and atmospheric forces also influence Amazonian rainfall (see Cox et al., 2004; Huntingford et al., 2004). Hence, it is necessary to combine the advances in understanding of atmosphere-land surface water and energy exchanges that have been gained through LBA with other recent progress made in 
understanding the relative importance of land surface fluxes, moisture transport from the Atlantic, and large-scale atmospheric instability in controlling the basin-scale precipitation climatology.

Most previous investigations on how the land surface could influence rainfall have focused on the wet season or on annual precipitation amounts (e.g. Dickinson and Henderson-Sellers, 1988; Cox et al., 2000; and many more). However, a longer dry season could be much more devastating to the Amazonian ecosystem than a moderate decrease of rainfall during the wet season (e.g. Nobre et al., 1991; Condit et al., 1995; Williamson et al., 2000), even though the former may reduce the annual rainfall amount by a similar or smaller amount. The dynamics of the precipitation system also suggest that the transition from dry to wet season (referred to hereafter as the transition) may be susceptible to the influences of land surface changes. Rainfall interactions with large-scale, low-level convergence and higher surface wetness during the wet season tend to reinforce conditions favourable for rainfall until the seasonal maximum of solar radiation moves away from that region. In contrast, the transition season requires that the surface dryness and inversion at the top of the boundary layer be overcome. These more stringent requirements have to be met in the absence of the summer large-scale circulation pattern favourable for convection. Thus, land surface conditions may have a greater influence during the transition season than during the wet season. Comparative (dry and wet season; forest and pasture) observations of the convective boundary-layer (e.g. Fisch et al., 2004), numerical experiments of land use, and observations of the interannual variations in Amazonian rainfall all support this contention. For example, Polcher (1995) has shown that replacing forest by pasture in Amazonia has the strongest influence on precipitation frequency over that region during the seasonal transition periods in August-September, November-December and April-May. Liebmann and Marengo (2001) also observed that the onset and ending dates contribute more to interannual changes of annual rainfall than does the precipitation intensity during the wet season.

The extent to which land surface changes affect rainfall over Amazonia depends on whether the main source of the moisture for rain- fall is evaporation of recycled water from the land surface or moisture transport from the Atlantic Ocean. If the land surface latent heat flux is a critical source of moisture, a pre-seasonal decrease of rainfall and accompanying lower surface wetness could significantly slow down the increase of atmospheric moisture during the transition and thereby delay the onset of the wet season. Conversely, if moisture transport, driven by the continent-ocean surface sensible heat flux gradient, is the main source of moisture, a preseasonal drought would enhance the land surface sensible heat flux and hence the gradient between land and ocean. This could strengthen the moisture transport and accelerate, rather than decelerate, the onset of the wet season. Past studies have focused on the relative importance of land surface recycling versus large-scale moisture transport in the wet season. Recently however, $\mathrm{Li}$ and $\mathrm{Fu}$ (2004) have found that land surface latent heat flux is a more important source of atmospheric moisture than large-scale moisture transport during the dry season and early stages of the transition season. Large-scale transport becomes a more important source of moisture as the onset approaches and during the wet season. This seasonality is supported by the seasonal variation of $\delta \mathrm{O}^{18}$ reported by Salati et al. (1979), whose results have shown that the weak longitudinal gradient of $\mathrm{O}^{18}$ depletion $\left(\delta \mathrm{O}^{18}\right)$ across Amazonia agrees approximately with that expected from a $50 \%$ recycling rate (Dall'Dlio et al., 1979) during the dry season. During the wet season, the steep longitudinal gradient of $\delta \mathrm{O}^{18}$ suggests that moisture transport is the primary source of water vapour. Early onset of the rainy season can lead to a steep longitudinal gradient of $\delta \mathrm{O}^{18}$ from coastal to inland Amazonia compared to the "normal" values for the OctoberDecember season. Evidently, the land surface water recycling during dry and transition seasons may amplify rainfall more in those periods than during the wet season.

This paper aims to assess the potential impact of land surface changes on the onset of the wet season in Amazonia. To accomplish this, we will examine the importance of land surface conditions in driving the transition process, relative to those of large-scale moisture transport and atmospheric circulation changes. We will also explore the implications for the impacts of land 
use on rainfall climatology and interannual variation, and discuss potential applications of LBA observations for validating our results.

\section{Data and methods}

We use the six-hour instantaneous ECMWF reanalysis (ERA) on $2.5^{\circ}$ latitude by $2.5^{\circ}$ longitude resolution for the period of 1979 to 1993 and in situ measurements of land surface sensible and latent heat fluxes provided by the AngloBrazilian Amazonian Climate Observation Study (ABRACOS, see Gash and Nobre, 1997). Detailed evaluations of ERA precipitation and related atmospheric thermodynamic and dynamic fields by observations are given by $\mathrm{Fu}$ et al. (2001) and $\mathrm{Li}$ and $\mathrm{Fu}$ (2004). These evaluations suggest that ERA can qualitatively capture the changes of rainfall at pentad (5 day average) resolution during the transition from dry to wet season ( $\mathrm{Li}$ and $\mathrm{Fu}, 2004)$. The comparison with radiosonde measurements by $\mathrm{Fu}$ et al. (2001) suggests a difference of less than $1 \mathrm{~K}$ in the climatological monthly mean temperature profiles and less than $1 \mathrm{~g} \mathrm{~kg}^{-1}$ in water vapour mixing ratio at Manaus $\left(3^{\circ} \mathrm{S}, 60^{\circ} \mathrm{W}\right)$ and Belém $\left(1.5^{\circ} \mathrm{S}, 49^{\circ} \mathrm{W}\right)$. The discrepancies in zonal and meridional wind profiles are less than $2 \mathrm{~ms}^{-1}$ below $200 \mathrm{hPa}$. In addition to these general agreements with observations, Marengo et al. (2001) have found that major characteristics of the large-scale circulation associated with wet season onset derived from ERA are consistent with those of the National Centers for Environmental Prediction (NCEP) reanalysis.

Betts and Jakob (2002) have compared the ECMWF short-term forecast to observations from the Wet Season Atmospheric Mesoscale Campaign of the LBA. The ECMWF model is able to qualitatively capture the patterns and relative importance of daily surface flux for wet season conditions, although discrepancies are found in the diurnal cycle of the boundary layer. It tends to overestimate the net radiative flux by as much as $10 \%$. This extra incoming energy is largely balanced by a greater latent heat flux than was observed in the micrometeorological observations.

Can the ERA adequately represent the changes of land surface sensible and latent heat fluxes? This question is addressed using the microme-

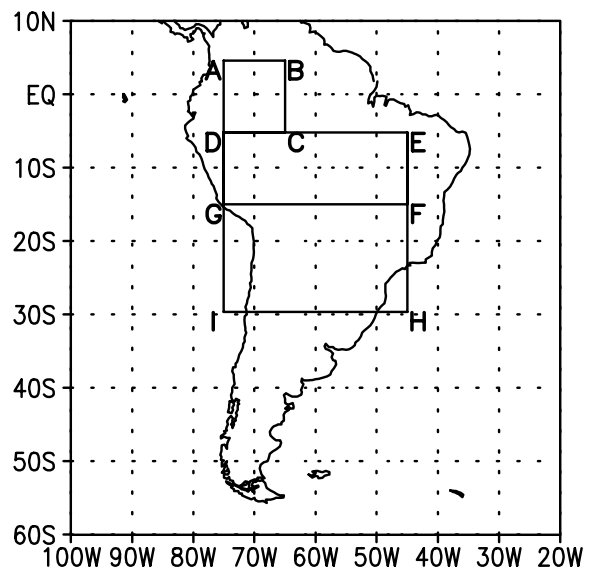

Fig. 1. The domains for $\mathrm{V}$-index $\left(5^{\circ} \mathrm{S}-5^{\circ} \mathrm{N}\right.$ and $65^{\circ}-$ $\left.75^{\circ} \mathrm{W}, \mathrm{ABCD}\right)$, Southern Amazonia region $\left(5^{\circ}-15^{\circ} \mathrm{S}\right.$ and $\left.45^{\circ}-75^{\circ} \mathrm{W}, \mathrm{DEFG}\right)$ and geopotential height at $200-\mathrm{hPa}$ $\left(5^{\circ}-30^{\circ} \mathrm{S}\right.$ and $\left.45^{\circ}-75^{\circ} \mathrm{W}, \mathrm{DEHI}\right)$, respectively

teorological measurements provided by ABRACOS at the forest site in Reserva Jaru $\left(10.08^{\circ} \mathrm{S}, 61.93^{\circ} \mathrm{W}\right)$, Rondônia, for the transition periods in 1992 and 1993. ABRACOS, observations were chosen because they overlap with the period of the available ERA. The values shown in Fig. 2 are pentad daily average fluxes. Because the ABRACOS surface fluxes were measured at one observational tower embedded in the $2.5^{\circ}$ grid of the ERA, a complete agreement between the ERA and the ABRACOS data should not be expected. Figure 2 shows that the general trends of surface latent fluxes assimilated by ERA agree well with the observations prior to early September. This agreement during the early stage of the transition is likely to support an adequate initiation of the transition in ERA because the increase of latent surface heat flux dominates the increase of the local moist static energy ( $\mathrm{Li}$ and $\mathrm{Fu}, 2004)$. ERA significantly underestimates the surface latent heat flux between mid-September and mid-October (from the $50^{\text {th }}$ to $57^{\text {th }}$ pentad). However, these discrepancies on this stage of the transition should have a limited influence because the transition is now increasingly dominated by changes in the large-scale circulation. ERA underestimates the surface sensible heat flux by as much as $50 \%$ prior to late September (the $52^{\text {nd }}$ pentad), but overestimate the increase of the sensible flux during the transition. Culf et al. (1998) have shown that the ECMWF model underestimates the surface solar flux at Reserva Jaru, especially during May to August due to errors in the 


\section{Surface heat fluxes comparison}

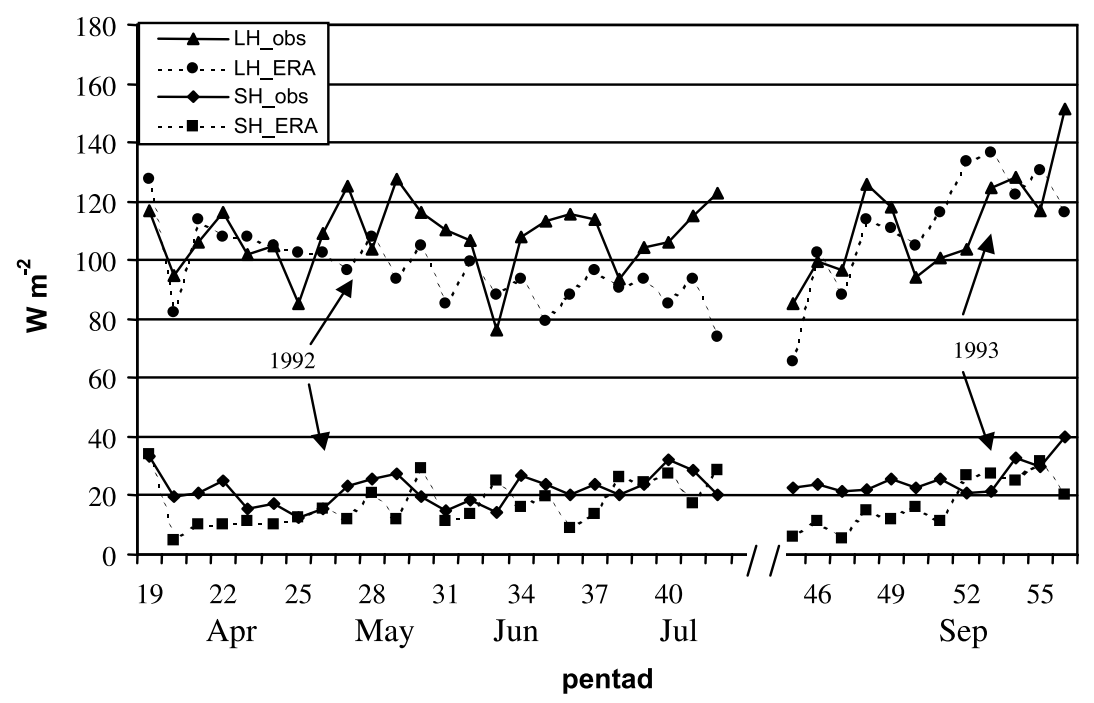

Fig. 2. Time series of the surface sensible (SH) and latent (LH) heat fluxes over the 1992 and 1993 transition seasons. The surface fluxes obtained from ERA are plotted in dashed curves with squares (SH) and dots (LH), respectively. The surface fluxes obtained from in situ ABRACOS observations are plotted in solid curves with diamonds (SH) and triangles (LH), respectively. The numbers of pentads in the abscissa are determined by their calendar dates. The ABRACOS observations of $\mathrm{SH}$ and $\mathrm{LH}$ are obtained from the tower measurements at the forest site in Reserva Jaru, Rondônia $\left(10.08^{\circ} \mathrm{S}, 61.93^{\circ} \mathrm{W}\right)$. The ERA SH and LH are obtained from the $2.5^{\circ}$ grid box overlap with this ABRACOS site. The unit is $\mathrm{W} \mathrm{m}^{-2}$

predicted cloud cover. This underestimation of surface solar flux may contribute to the underestimation of the dry season surface latent and sensible heat flux as shown in Fig. 2.

We use surface sensible and latent heat fluxes, precipitation, temperature, humidity, winds, and geopotential height from ERA data at 13 levels ranging from 1000 to $100 \mathrm{hPa}$. Because the peak of the rainy season varies from July in the northern areas of Amazonia to January in southern areas, we choose a smaller domain, $5^{\circ}-15^{\circ} \mathrm{S}$ and $45^{\circ}-$ $75^{\circ} \mathrm{W}$, referred to as the Southern Amazonian region (Fig. 1, domain DEFG) in our analysis. We expand the southern boundary of this domain southward to $30^{\circ} \mathrm{S}$ (Fig. 1, domain DEHI) to diagnose the changes of $200 \mathrm{hPa}$ geopotential height and completely include the upper tropospheric circulation associated with the Bolivian High.

Following $\mathrm{Li}$ and $\mathrm{Fu}$ (2004), we have computed surface Bowen ratio, defined as the ratio of surface sensible vs. latent heat flux, equivalent potential temperature and its tendency at $850 \mathrm{hPa}$ $\left(\theta_{e, 850 \mathrm{hPa}}\right.$ and $\left.\frac{\partial \theta_{e}}{\partial t}\right|_{850 \mathrm{hPa}}$, respectively), and the contributions of the temperature and specific humidity tendencies ( $\frac{\partial T}{\partial t}$ and $\frac{\partial q}{\partial t}$, respectively) to $\left.\frac{\partial \theta_{e}}{\partial t}\right|_{850 \mathrm{hPa}}$. Convective Available Potential Energy
(CAPE) and Convective Inhibition Energy (CINE) are computed as by Williams and Rennó (1993). The V-index is used to represent the cross-equatorial flow over Amazonia. It is defined by Wang and $\mathrm{Fu}$ (2002) as the area averaged meridional wind in equatorial western Amazonia $\left(5^{\circ} \mathrm{S}-5^{\circ} \mathrm{N}, 65^{\circ} \mathrm{W}-75^{\circ} \mathrm{W}\right.$, domain $\mathrm{ABCD}$ in Fig. 1). All these variables, especially those nonlinearly related to the input fields, are first computed from instantaneous input values at six-hour intervals. They are then averaged over a period of five days (a pentad). The pentad resolution has been shown to minimize daily variations and noise, but still be fine enough to resolve the changes during the transition over Amazonia (e.g. Kousky, 1988; Horel et al., 1989).

Again following $\mathrm{Li}$ and $\mathrm{Fu}$ (2004), the onset is defined as the pentad before which rain rate is less than the climatological annual mean rain rate in the ERA $\left(6.1 \mathrm{~mm} \mathrm{day}^{-1}\right)$ during 6 out of 8 preceding pentads and after which rain rate is greater than $6.1 \mathrm{~mm} \mathrm{day}^{-1}$ during 6 out of 8 subsequent pentads. This definition is essentially similar to those of Kousky (1988) and Marengo et al. (2001), but uses the climatological annual mean rain rate as the threshold to determine the 
wet season onset, rather than a subjectively determined rain rate threshold.

In this paper, we will compare individual transitions in years of early and late onsets to that of a "normal" onset, as well as the "climatological" transition. The latter is represented by a composite analysis of the fifteen transitions between 1979 and 1993. The 95\% confidence level of each composite variable is computed based on the student- $t$ distribution. Because of the large year-to-year variation of the onset date over Amazonia, our composite is centred at the pentad of the onset (defined as pentad 0) of each year, rather than by calendar dates. The $n^{\text {th }}$ pentad before the onset at each year is defined as pentad $-n$, and the $n^{\text {th }}$ pentad after the onset is defined as pentad $n$. This approach enables us to more clearly focus on the large-scale circulation change associated with the evolution of the onset process, instead of calendar dates, over the Southern Amazonian region.

\section{Role of the land surface in the transition from dry to wet season}

\subsection{In a climatological transition}

$\mathrm{Li}$ and $\mathrm{Fu}$ (2004) have presented a thorough examination of the processes that drive the transition from dry to wet season. Figure 3 illustrates

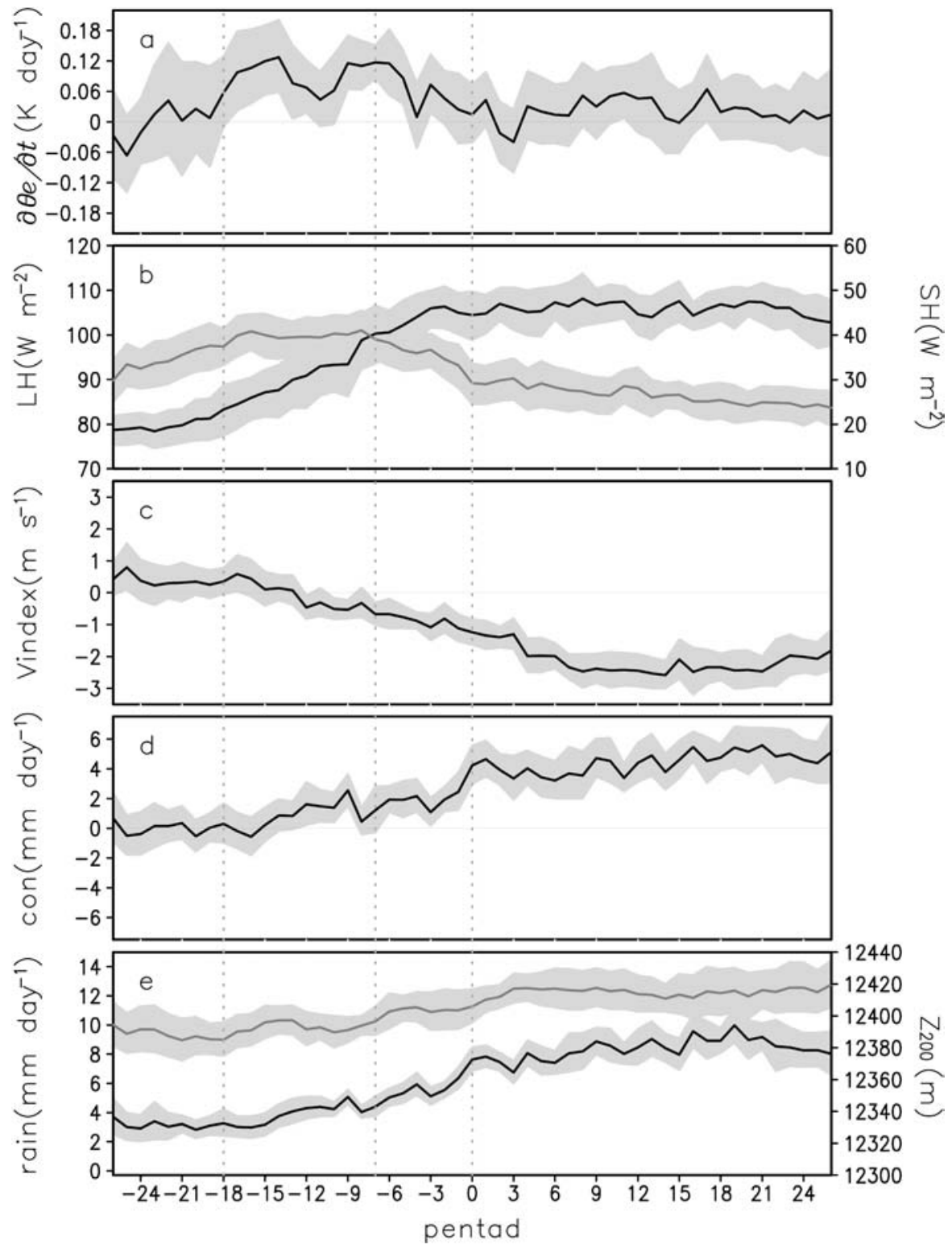

Fig. 3. Fifteen-year composite annual cycles of (a) $\left.\frac{\partial \theta_{e}}{\partial t}\right|_{850 \mathrm{hPa}}$; (b) surface latent heat flux (solid line) and sensible heat flux (grey line); (c) V-index (solid line) (d) net moisture convergence; (e) rain rate (solid line) and areal averaged geopotential height at 200-hPa (grey line, unit: metre). All variables are computed for the Southern Amazonian domain, except for the $200-\mathrm{hPa}$ geopotential height, which is obtained over $5^{\circ}-30^{\circ} \mathrm{S}, 45^{\circ}-75^{\circ} \mathrm{W}$. Shaded areas represent confidence interval at $95 \%$ significance for each variable 
how the relative importance of land surface fluxes versus large-scale circulation changes through different phases of the transition. The initiating phase begins when the local increase of $\theta_{e, 850-\mathrm{hPa}}$ becomes significantly positive at the $-18^{\text {th }}$ pentad of the transition (Fig. 3a). It ends when the transition of the large-scale circulation becomes significant at the $-7^{\text {th }}$ pentad (Fig. 3c), namely, the V-index reverses to northerly and the moisture converges. Prior to the initiating phase, the land surface fluxes, especially the sensible heat flux, already begin to increase (Fig. 3b). In contrast, the cross-equatorial flow, moisture divergence (Fig. 3d) and the geopotential height at 200-hPa (Fig. 3e), remain the same as those of the dry season. The increase of $\theta_{e, 850 \mathrm{hPa}}$ is insignificant.

During the initiating phase, moist static energy increases rapidly in the lower troposphere, as shown by strong positive $\left.\frac{\partial \theta_{e}}{\partial t}\right|_{850 \mathrm{hPa}}$. The latent flux increases rapidly (Fig. 3b), but land surface sensible flux heat no longer increases. The changes of the large-scale circulation are still insignificant (Fig. 3c-e). To help determine whether it is increases of local land surface sensible heat flux, increases of latent heat fluxes or change in large-scale circulation which initiate the transition, we need to clarify: a) what contributes to the increase of $\theta_{e, 850 \mathrm{hPa}}$; and $\mathrm{b}$ ) what causes the initial increase of rainfall during this phase. Figure $4 \mathrm{a}$ shows that the increase of moisture makes a greater contribution to the positive $\left.\frac{\partial \theta_{e}}{\partial t}\right|_{850 \mathrm{mb}}$ during the initiating phase than does the increase of temperature. This suggests that the increase of either evaporation from the land surface or large-scale moisture transport is the main contributor to the increase of $\theta_{e, 850 \mathrm{hPa}}$. Figure $3 \mathrm{e}$ shows that rainfall begins to increase at the $-15^{\text {th }}$ pentad when the V-index is still southerly and moisture diverges from the Southern Amazonian domain. However, the CINE has already decreased sharply, and CAPE increased (Fig. 4b). These are expected from the strong increase of $\theta_{e, 850 \mathrm{hPa}}$ shown in Fig. 3a. Such

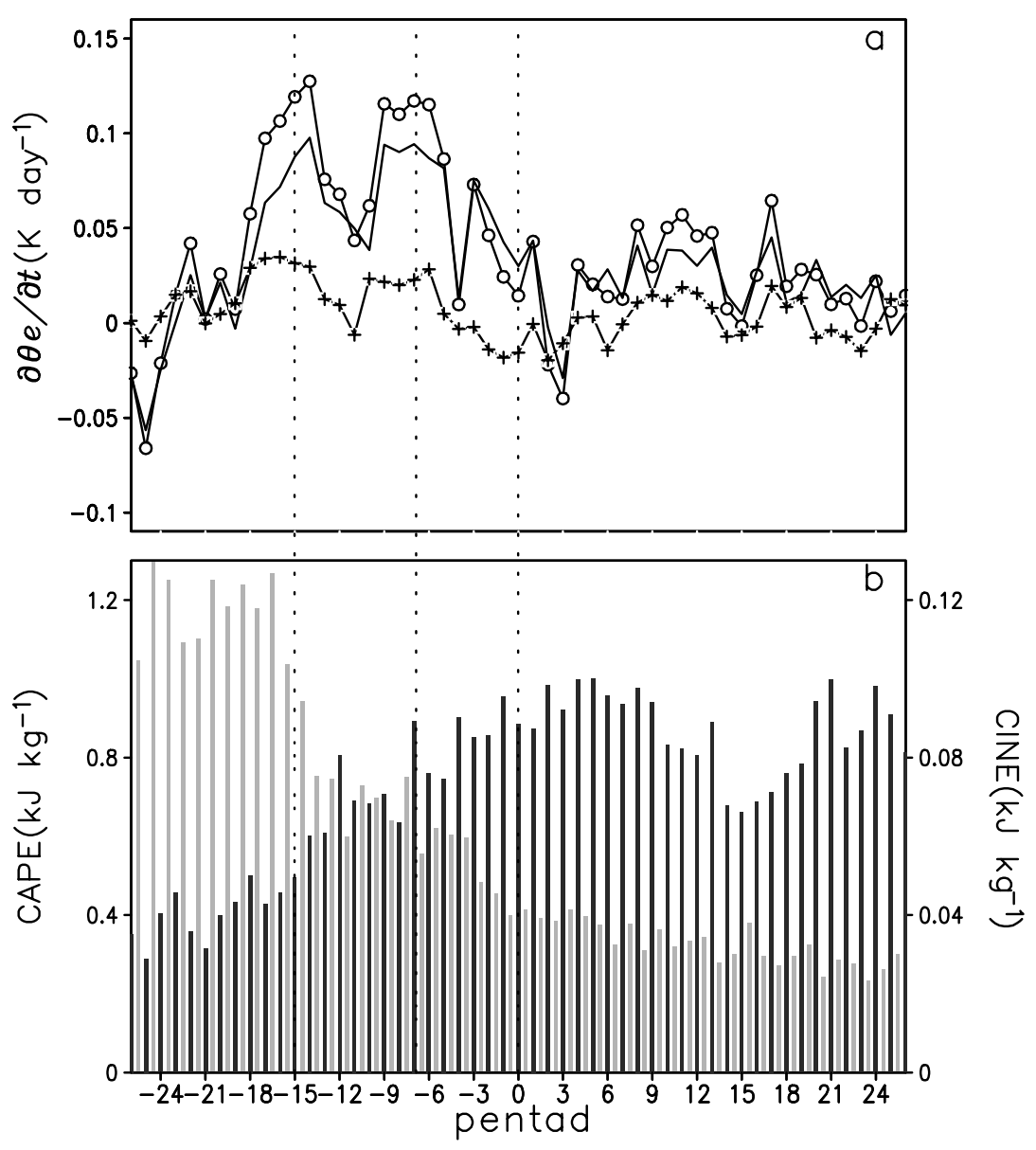

Fig. 4. As in Fig. 3, but for (a) $\left.\frac{\partial \theta_{e}}{\partial t}\right|_{850 \mathrm{hPa}}$ (solid line with open circles), contribution of $\frac{\partial T}{\partial t}$ (dash line with crosses) and $\frac{\partial q}{\partial t}$ (solid line) to $\left.\frac{\partial \theta_{e}}{\partial t}\right|_{850 \mathrm{hPa}}$; (b) CAPE (black) and CINE (grey). These variables are averaged over the Southern Amazonian domain 
strong changes of CINE and CAPE prior to the transition of the large-scale circulation must result from a rapid increase of land surface latent heat flux. Thus, the increase of the land surface latent heat flux must initiate the increase of rainfall.

Although the surface temperature difference between Southern Amazonia and the tropical Atlantic also increases $\left(1^{\circ} \mathrm{C}\right)$, it is probably not the main cause of the reversal of the V-index. Firstly, the continent-ocean temperature difference in the middle to upper troposphere $(500 \mathrm{hPa}$ to $200 \mathrm{hPa})$, a measure of the thermal forcing due to continent-ocean temperature gradient, is only about $1 / 5$ of those observed for the Indian and Australia monsoons (Webster et al., 1998). Thus the thermal forcing due to the temperature gradient over Amazonia is probably too weak. Secondly the continent-ocean surface temperature gradient decreases as the northerly cross-equatorial flow and moisture convergence increase during the developing phase. This decrease suggests that the transition of the large-scale circulation is not controlled by the continent-ocean surface temperature gradient. The numerical experiments of Rind and Rossow (1984) have shown that heating in the middle troposphere more effectively forces the largescale atmospheric circulation than does thermal forcing near the surface. Thus, the increase of local rainfall can more effectively force the transition of the large-scale circulation over Amazonia than can the increase of continent-ocean surface temperature gradient.

During the developing phase (from the $-7^{\text {th }}$ to $0^{\text {th }}$ pentad), the rate of increase of $\theta_{e, 850 \mathrm{hPa}}$ is reduced (Fig. 3a), but the northerly crossequatorial flow and large-scale moisture convergence increase with time (Fig. $3 \mathrm{c}$ and $\mathrm{d}$ ). Thus, the changes in the large-scale circulation become increasingly important in driving the transition. Because the surface temperature gradient between land and ocean decreases (not shown) and the land surface fluxes do not increase, the transition must be accelerated by the positive response of the large-scale moisture convergence and the upper troposphere geopotential height to the increase of rainfall. Such positive response represents the largescale lateral ventilation of the atmosphere driven by continuously increasing solar heating over
Amazonia (e.g. Wallace, 1992; Pierrehumbert, 1995).

The climatology of the transition from dry to wet season (shown in Fig. 3) suggests that, in general, the increase of land surface fluxes destabilizes the lower troposphere and initiates the seasonal increase of rainfall. The latter accelerates the transition of the large-scale circulation and leads to the wet season onset.

\subsection{In early and late onsets}

The importance of the land surface latent heat flux in initiating the transition shown in Figs. 3 and 4 implies that changes in land surface fluxes, in addition to the externally forced atmospheric large-scale circulation change, could accelerate or delay the wet season onsets on an interannual scale. To verify this contention, we have selected 1979, 1984, and 1986 as examples of earlier or delayed onsets during the period of our analysis (1979-1993). These years are chosen because their onset dates differ from the fifteen-year average onset date by more than one month. We also use 1990 as an example of a normal onset year.

In a "normal" onset year such as 1990, the Bowen ratio ranged between 0.4 and 0.6 during the dry season and between 0.2 and 0.35 during the wet season (Fig. 5), i.e. within the range of its observed values at the ABRACOS site (Manzi and Planton, 1996; Silva Dias and Regnier, 1996). Considering the uncertainties of the ERA land surface fluxes, we can only qualitatively discuss their differences between normal, early, and late onsets. In 1990, surface sensible heat flux averaged over the Southern Amazonian domain began to increase in early June (pentad 30 ), and surface latent heat flux in mid-July (pentad 38). Following the increase of surface latent heat flux, humidity at $850 \mathrm{hPa}$ and CAPE all increased, and CINE decreased rapidly in early August (pentad 44, Fig. 7). The V-index reversed in mid-October (pentad 57) and the $200 \mathrm{hPa}$ geopotential height began to increase in late September (pentad 53, Fig. 8).

\subsubsection{Early onset}

In 1979, the wet season began during 28 August2 September (Fig. 6b), about two months earlier than the average onset date (2-6 November). 

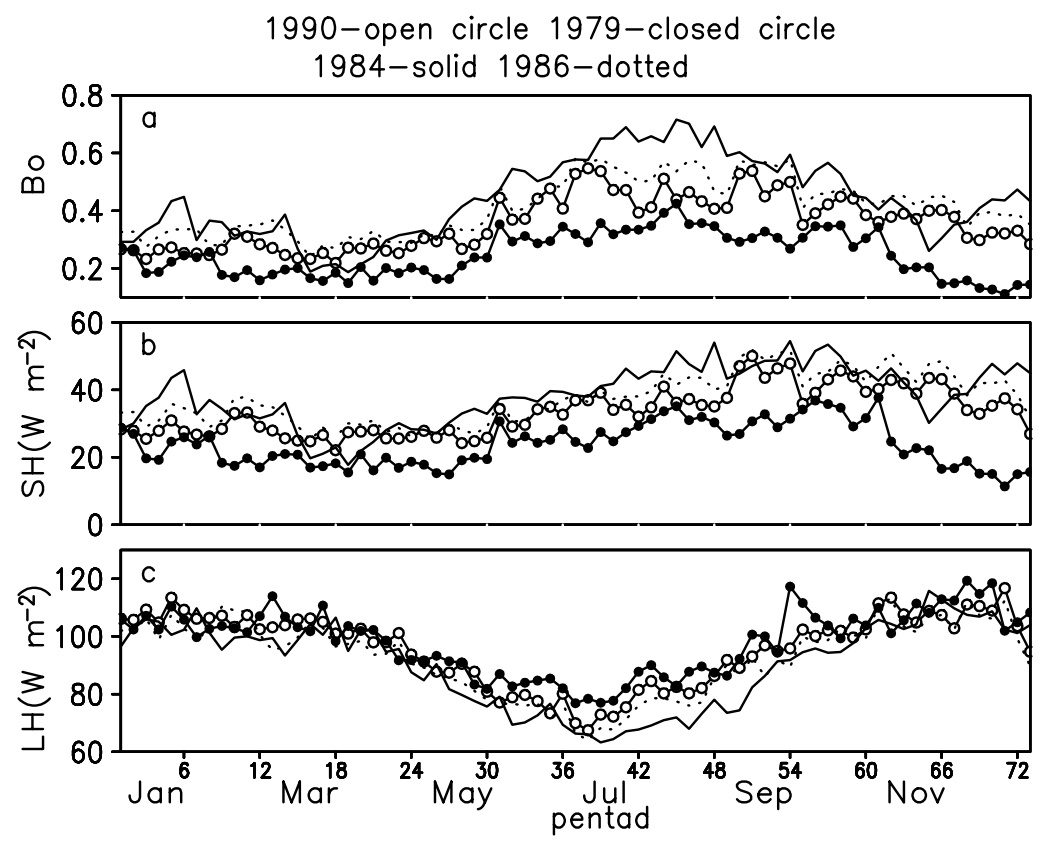

Fig. 5. a) Annual cycles of area averaged a) Bowen ratio; b) surface sensible heat fluxes; c) surface latent heat fluxes for 1990 (curve with open circles), 1979 (curve with closed circles), 1984 (solid curve) and 1986 (dotted curve), respectively, for the Southern Amazonian domain

area mean pt(dotted) $q$ (solid with circle) \& ept (solid)

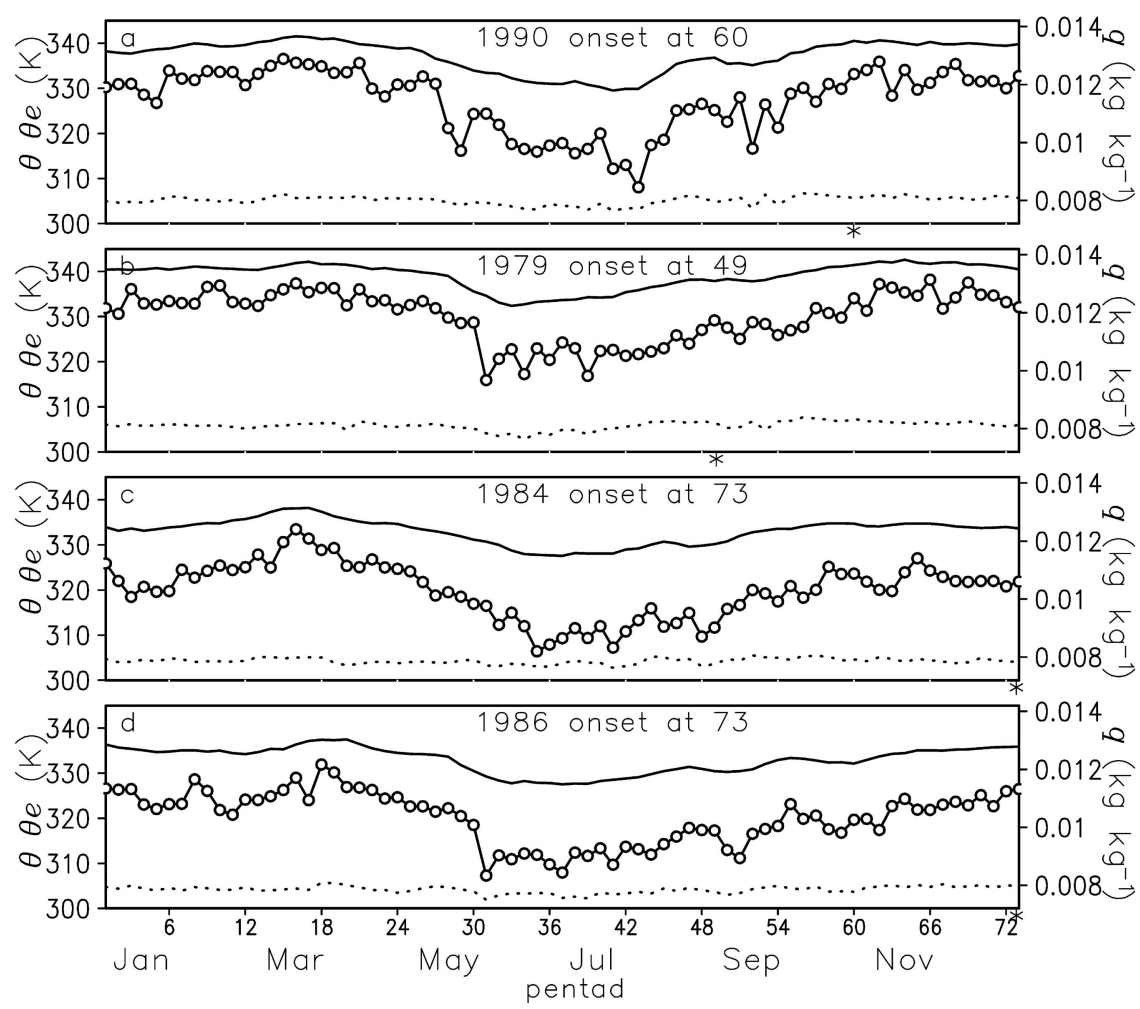

Fig. 6. Annual cycles of area averaged $\theta_{e, 850 \mathrm{hPa}}$ (solid curve), potential temperature at $850-\mathrm{hPa}\left(\theta_{850 \mathrm{hPa}}\right.$, dotted curve) and $q_{850 \mathrm{hPa}}$ (curve with open circles) for a) 1990 ; b) 1979 ; c) 1984; and d) 1986, respectively. The onset pentad of each year is marked by "**" in each panel
Compared to the dry season of 1990, the Bowen ratio was as much as $40 \%$ lower during August and September, as a result of both lower surface sensible heat flux (by $\sim 25 \%$ or $10 \mathrm{~W} \mathrm{~m}^{-2}$ ) and higher latent heat flux (by $\sim 10 \%$ or $10 \mathrm{~W} \mathrm{~m}^{-2}$ ). Specific humidity at $850 \mathrm{hPa}\left(q_{850 \mathrm{hPa}}\right)$ followed the higher surface latent heat flux, and was also $10 \%$ higher (Fig. 6). Evidently, the Bowen ratio was lower, the land surface wetter and the lower troposphere more humid during the 1979 dry and early transition seasons. CINE in June was $25 \%$ lower, and reduced quickly to $25-50 \%$ of its 
normal dry season values in early July (pentad 36), before the northerly reversal of the V-index. In contrast, CAPE and the $200 \mathrm{hPa}$ geopotential height were similar to those of 1990 during the peak dry season, suggesting that the middle and upper troposphere in the dry season were as stable as in a normal dry season. Thus, wetter land surface and higher surface latent heat flux must contribute to the higher $q_{850 \mathrm{hPa}}$ and lower CINE found in the 1979 dry and early transition seasons.

The transition of the large-scale circulation also began earlier in 1979 than that in 1990 . The V-index reversed to northerly in late July (Fig. 8b) almost three months earlier than in 1990. In mid-August (pentad 45), when the northerly $\mathrm{V}$-index increased to $2 \mathrm{~m} \mathrm{~s}^{-1}$, the increase of $q_{850 \mathrm{hPa}}, \theta_{e, 850 \mathrm{hPa}}$ and CAPE also accelerated. Clearly, the earlier transition of the large-scale circulation also contributes to the earlier wet season onset in 1979. Although our diagnostic results cannot directly determine what causes the earlier reversal of the $\mathrm{V}$-index in 1979, the warmer land surface temperatures caused stronger continent-ocean surface temperature differences in 1979 than in 1990 throughout most of the transition period (not shown). Thus, both the earlier increase of rainfall and warmer land surface temperature may contribute to the earlier northerly reversal of the cross-equatorial flow in 1979.

Our analysis of the 1979 case suggests that a wetter land surface in the dry season can cause an abnormally lower CINE, and thus promote an earlier and more rapid increase of rainfall during the early phase of the transition. The anomalous high rainfall and the earlier reversal of the crossequatorial flow apparently led to the earlier wet season onset.

\subsubsection{Late onsets}

Compared to the "normal" 1990, the wet season onsets were delayed by almost two months in both 1984 and 1986. Surface latent heat flux in both of these years began to increase in early July (pentads 38 and 39), as it did in 1990 (Fig. 5b). However, the sensible heat flux was higher and the latent heat flux was lower, especially during the 1984 dry season, so the Bowen ratio was higher than normal in July and October by as much as $40 \%$ in 1984 and $20 \%$ in 1986 (Fig. 5a). These surface flux anomalies clearly indicate a drier land surface,

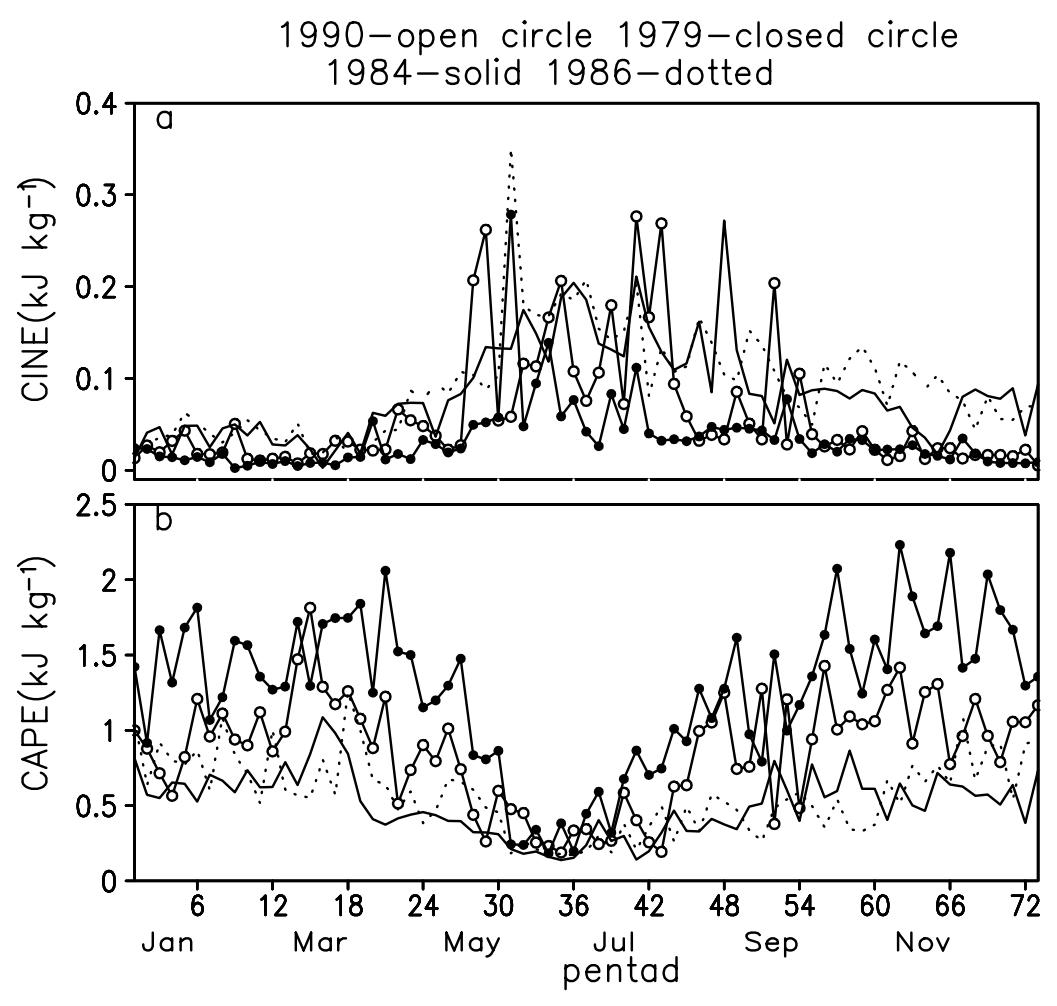

Fig. 7. As in Fig. 5, but for a) CINE; and b) CAPE of 1990 (curve with open circles), 1979 (curve with closed circles), 1984 (solid curve) and 1986 (dotted curve), respectively 

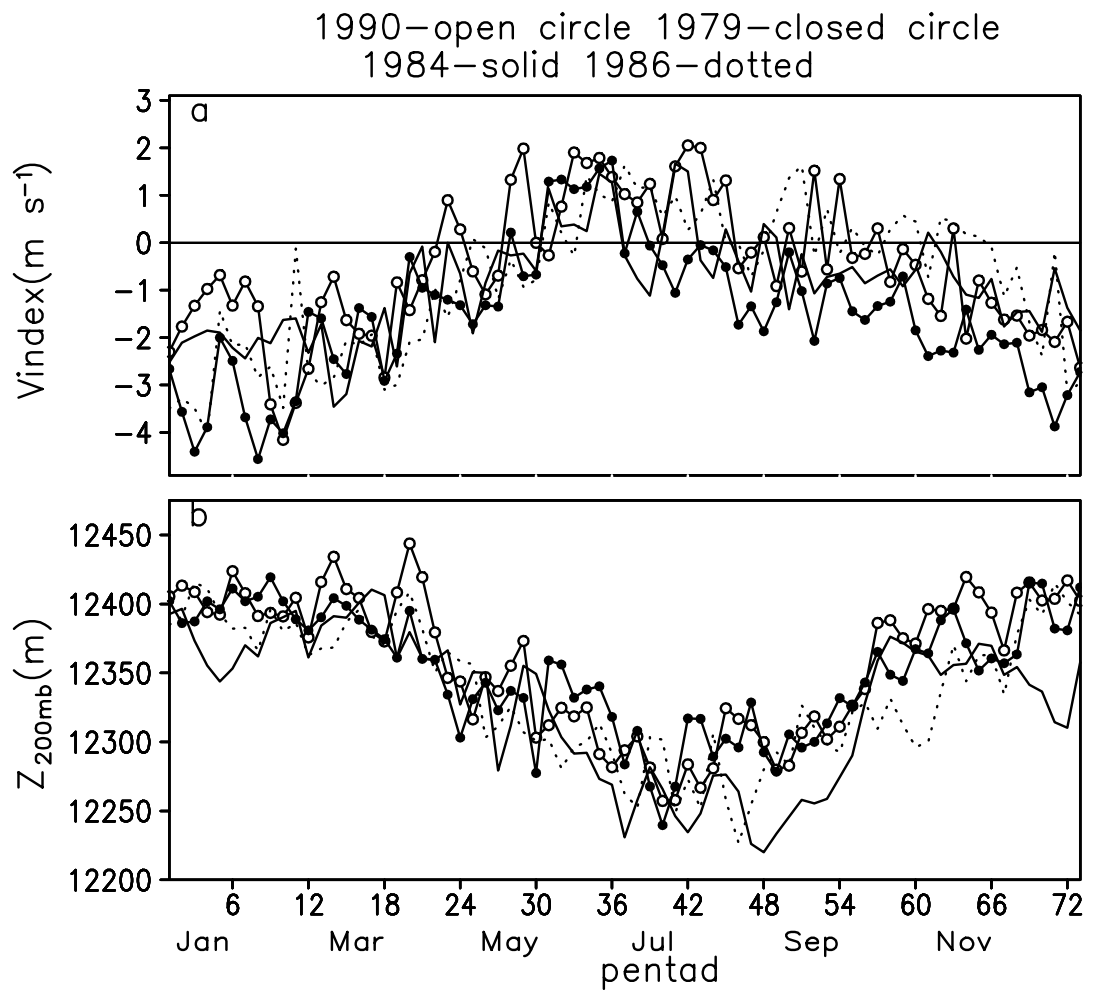

Fig. 8. As in Fig. 7, but for a) the Vindex, and b) 200-hPa geopotential height over the area of $5^{\circ}-30^{\circ} \mathrm{S}, 45^{\circ}-$ $75^{\circ} \mathrm{W}$ (unit: metre) especially in 1984. As expected from such dry land surface conditions, CINE was 2 to 3 times higher during August to mid-September of 1984 and 1986. CINE remained higher than in 1990 through the rest of the transition until the wet season onset.

During the fifteen years of our analysis, the wet season onsets appear to occur only after CINE reduces to $50 \mathrm{~J} \mathrm{~kg}^{-1}$ or less (Fig. 7a). CINE also remains lower than this value throughout the wet season. This result from ERA is consistent with that estimated from multi-year radiosonde data for the Southern Amazonian domain (Fu et al., 1999). Thus, a low enough CINE, for example, $50 \mathrm{~J} \mathrm{~kg}^{-1}$ or less, may be a necessary condition for the wet season to occur over Amazonia. If so, CINE in both 1984 and 1986 were too high for wet season onset from June to the end of December. This excess CINE alone can generally explain the delay of the wet season onsets in both 1984 and 1986.

The large-scale circulation may have also influenced the wet season onset during the developing phase. The anomalous land surface dryness was stronger in 1984 than in 1986, but the delays of the wet season onset appear to be the same. As shown in Fig. 8a, the V-index reversed to north- erly in early September in 1984 and early December in 1986. Although the northerly Vindex in 1984 remained weak relative to that of 1990 until late November (pentad 65), it could partially offset the influence of the stronger land surface dryness and contribute to a rapid decrease of CINE in early September (Fig. 7a). The $200 \mathrm{hPa}$ geopotential height also increased rapidly starting from the end of September 1984 (the $54^{\text {th }}$ pentad), following the northerly reversal of the $\mathrm{V}$-index. Thus, the earlier initiation of the large-scale circulation transition in 1984 may have partially offset the effects of the stronger surface dryness.

\section{Discussion}

\subsection{Relative importance of land surface and large-scale circulation in determining the wet season onset}

Our analysis suggests that the land surface conditions during dry and early transition seasons can contribute significantly to the interannual changes of the wet season onset. For example, the humid surface conditions in the 1979 dry season supported higher surface latent heat 
fluxes, weaker CINE, and stronger CAPE, and in turn a stronger and more rapid increase of convection. These factors and the earlier reversal of the cross equatorial flow lead to an earlier increase of rainfall and geopotential height in the upper troposphere during the transition, and hence an earlier wet season onset. Conversely, the lower surface latent heat flux and drier lower troposphere during dry seasons in 1984 and 1986 appear to cause higher CINE and lower CAPE during the transition, and therefore a delayed wet season onset in both years, even with the normal reversal of the cross-equatorial flow in 1984. On the other hand, the earlier reversal of the cross-equatorial flow in 1984 may have partially offset the delay expected from the stronger land surface dryness. Overall, our results imply that a drier land surface during the dry season should delay, not accelerate the wet season onset over Amazonia.

Changes in the land surface conditions and large-scale atmospheric circulation cannot be separated completely. The surface conditions of the dry and transition seasons are largely a result of both historic and current atmospheric conditions. The externally forced atmospheric circulation changes, such as those forced by El Niño-Southern Oscillation (ENSO), are known to influence the wet season onsets. This paper focuses on influence of the land surface conditions on rainfall during the dry and transition seasons, a previously overlooked issue. The role of the atmosphere and land surface type in affecting surface conditions during the dry and transition seasons will be addressed at a later date.

The influence of excess soil moisture on an early wet season onset can be different from that of dry soil on a late wet season. The land surface wetness and static instability in the lower troposphere only provide a necessary, not a sufficient, condition for wet season onset. Thus, a drier land surface delays the wet season onset, whereas a wet land surface during the dry season does not necessarily result in an earlier onset if the transition of the large-scale circulation is delayed by external forcing, such as that of surface temperature anomalies in the adjacent oceans. In fact, delayed wet season onsets following anomalous, humid dry seasons have been observed during El Niños.

\subsection{Impact of land use on the precipitation regime over the Amazonia}

Previous land use studies have consistently shown that the removal of the rainforest reduces canopy interception of precipitation, increases runoff, and increases the exposure of the surface soil to solar radiation (e.g. Salati and Vose, 1984; Dickinson and Henderson-Sellers, 1988; Nobre et al., 1991; Hodnett et al., 1996; Souza et al., 1996; Werth and Avissar, 2002). The loss of deep roots found in the rainforest (e.g. Dawson, 1993; Nepstad et al., 1994) would disconnect surface soil from moisture in the underlying deep soil. All these changes tend to accelerate the loss of soil moisture immediately after rain events, consequently reducing the surface wetness and latent heat flux during the dry season (e.g. Nobre et al., 1996). Based on the mechanism suggested by our analysis, with forest removed, the transition from dry to wet season would be delayed and weakened, thereby increasing the length of the dry season. As shown by Gash and Nobre (1997), the land surface latent heat flux in the dry season (July) can be $30 \%$ lower, and the sensible heat flux can be $100 \%$ higher over a cleared area compared to that over the adjacent forested area. These observed changes are greater than the interannual changes of surface fluxes in 1984 and 1986 , which largely contribute to the delay of wet season onsets by 55 days. If we assume that the surface flux changes due to large-scale land use are comparable to those reported by Gash and Nobre (1997), these surface flux changes would significantly delay the wet season onset, possibly by up to a few months.

By the same token, such changes would also amplify and prolong droughts, such as those caused by El Niños. Compared to the areas with rainforest, the lower soil water storage would further reduce the surface latent heat flux during the droughts, thus requiring stronger moisture transport to support wet season onset. In reality, the influence of land use on the wet season onset and the length of dry season could depend on the patterns of land use and characteristic climate and ecological conditions that vary within Amazonia. Thus, the general hypothesis inferred from our results must be tested more thoroughly using global and regional climate models. These inferences may not be applicable to the easternmost 
parts of Amazonia, where oceanic influences dominate the precipitation climatology.

It is also possible that basin-scale land use change could so substantially decrease the surface soil moisture and land surface latent heat flux during the dry and transition seasons that the increase of sensible heat and of continentocean surface temperature gradient would become the main driver of the cross-equatorial flow reversal, as found for the Australia monsoon. With such changes, the diabatic heating in the middle troposphere produced by local rainfall in the early phase of the transition would be absent. The wet season onset could be delayed to summer, instead of spring, as is found for the Australia monsoon. Furthermore, the smaller temperature contrast between Amazonia and the tropical Atlantic Ocean compared to the continent-ocean contrast of the Austro-Asian monsoon systems implies a weaker seasonal reversal of the continent-ocean temperature gradient. Thus, a shift from predominately surface latent heat flux to sensible heat flux as the main initiator of the transition could substantially delay the wet season onset, resulting in a climate regime with a much longer and drier dry season.

\subsection{Potential of LBA observations \\ for determining the influence of land surface fluxes on seasonal transitions of Amazonian rainfall}

Although our results derived from ERA may clarify how to best use LBA and pre-LBA in situ observations to investigate the processes that determine the wet season onset, the ERA results may be inaccurate as to quantitative changes of the land surface fluxes. In particular, the surface fluxes and their climatic variability during dry and transition seasons as represented by ERA need to be evaluated by multi-year observations as obtained by combining the ABRACOS and LBA datasets. In addition, the comprehensive and year-round in situ LBA measurements represent the best available ground "truth" over Southern Amazonia for land surface fluxes from ground to canopy level, as well as soil moisture at various depths for different vegetation types. These LBA observations can be used to clarify the physical and biological processes that control surface fluxes and soil moisture during the transition seasons, and their interannual variations. As the LBA micrometeorological observations accumulate, especially through ENSO cycles, we will be able to evaluate changes in the land surface fluxes for at least several areas within Amazonia. They can also be used with satellite observations to examine the influences of atmospheric condition, such as rainfall and cloudiness, on the land surface conditions during dry and transition seasons. More importantly, the progress made by LBA in understanding the factors that control surface soil moisture and surface fluxes could lay the foundation for us to determine the influences of pre-seasonal and current rainfall on these land surface properties in our large-scale diagnostic studies of precipitation climatology.

\section{Conclusions}

We have analyzed the atmospheric and land surface conditions key to the wet season onset, the timing of which largely controls the length of the dry season. The dry season aspect of the precipitation climatology may be crucial to preserving current Amazonian ecosystems, but has not been previously examined nearly as thoroughly as have wet season rainfall changes. Our analysis of the fifteen years of ECMWF reanalysis suggests that the transition from dry to wet season in Southern Amazonia is mainly initiated by increases of surface latent flux and local precipitation. The latter provides an effective forcing for the reversal of the cross-equatorial flow, which causes net large-scale moisture convergence to the Southern Amazonian domain. The analysis of early and late wet season onsets on an interannual scale shows that a longer dry season with lower rainfall causes lower surface latent flux in the earlier transition periods. This results in a higher CINE and a lower CAPE, delays and weakens the initial increase of rainfall, and delays the transition of the large-scale circulation. Conversely, a wetter dry season leads to a higher surface latent heat flux and a weak CINE, providing a necessary condition for an earlier increase of local rainfall and a sooner wet season onset. The removal of the rainforest would result in a more rapid loss of soil moisture after 
rain events and thus drier surface soil and lower surface latent flux during the dry and transition seasons. If we assume that the changes of land surface fluxes due to land use are comparable to the differences between forest and pasture sites observed by ABRACOS (e.g. Nobre et al., 1996) and LBA, then these changes would be comparable or greater than interannual changes between early and late onsets. Thus, increased land use change could delay the wet season onset and prolong the dry season by as much as several months given a similar largescale atmospheric circulation pattern to today's. These inferences, if they can be validated by LBA observations, strongly suggest that more effort should be made to understand the impact of land use on the dry and transition seasons. Changes of precipitation during these periods may not only have greater ecological and economic impacts than a moderate reduction of wet season rainfall, but also have not received adequate attention.

\section{Acknowledgements}

The NOAA PACS project and NASA Global Water and Energy Cycle Program support this work. We thank Robert Dickinson and Jonathon Wright for helpful suggestions, Brant Liebmann and an anonymous reviewer for their insightful comments, and Margaret Sanderson Rae for her editorial assistance.

\section{References}

Betts AK, Jakob C (2002) Evaluation of the diurnal cycle of precipitation, surface thermodynamics, and surface fluxes in the ECMWF model using LBA data. J Geophys Res 107 (DZO): 8045, DOI: 10.1029/200/JD000427

Condit R, Hubbell SP, Forster RB (1995) Mortality rates of 205 geotropically tree and shrub species and the impact of a severe drought. Ecol Monogram 65: 49-439

Cox PM, Betts RA, Jones CD, Spell SA, Totter dell IJ (2000) Acceleration of global warming due to carboncycle feedbacks in a coupled climate model. Nature 408: 184-190

Cox PM, Betts RA, Collins M, Harris P, Huntingford C, Jones CD (2004) Amazon dieback under climate-carbon cycle projections for the $21^{\text {st }}$ century. Theor Appl Climatol (this issue)

Culf AD, Fisch G, Lean J, Polcher J (1998) A comparison of Amazonian climate data with general circulation model simulations. J Climate 11: 2764-2772

Dall'Dlio A, Salati E, Zepeda CE, Matsui E (1979) Model de fracionamento isotopico da agua na Bacia Amazonica. Acta Amazonia 9: 675-687
Dawson TE (1993) Hydraulic lift and water use by plants: Implications for water balance, performance, and plantplant interactions. Oecologia 95: 565-574

Dickinson RE, Henderson-Sellers A (1988) Modeling tropical land use: A study of GCM land-surface parameterization. Quart J Roy Meteor Soc 114: 439-462

Fisch G, Tota J, Machado LAT, Silva Dias MAF, Lyra RF da F, Nobre CA, Dolman AJ, Gash JHC (2004) The convective boundary layer over pasture and forest in Amazonia. Theor Appl Climatol (this issue)

Fu R, Zhu B, Dickinson RE (1999) How do atmosphere and land surface influence seasonal changes of convection in the tropical Amazon? J Climate 12: 1306-1321

Fu R, Dickinson RE, Chen M, Wang H (2001) How do tropical sea surface temperatures influence the seasonal distribution of precipitation in the equatorial Amazon? J Climate 14: 4003-4026

Gash JHC, Nobre CA (1997) Climatic effects of Amazonian deforestation: some results from ABRACOS. Bull Amer Meteor Soc 78: 823-830

Hodnett MG, Oyama MD, Tomasella J, Marques Filho A de O (1996) Comparison of long-term soil water storage behaviour under pasture and forest in three areas of Amazonia. In: Gash JHC, Nobre CA, Roberts JM, Victoria RL (eds) Amazonian deforestation and climate. Chichester: John Wiley \& Sons, pp 57-77

Horel JD, Hahmann AN, Geisler JE (1989) An investigation of the annual cycle of convective activity over the tropical Americas. J Climate 2: 1388-1403

Huntingford C, Harris PP, Gedney N, Cox PM, Betts RA, Marengo J, Gash JHC (2004) Investigating the potential for Amazonian "dieback" in a future climate using a GCM analogue model. Theor Appl Climatol (this issue)

Kousky VE (1988) Pentad outgoing longwave radiation climatology for the South American sector. Rev Bras Meteorol 3: 217-231

Li W, Fu R (2004) Transition of the large-scale atmospheric and land surface conditions from dry to wet season over the Amazon. J Climate (in press)

Liebmann B, Marengo JA (2001) Interannual variability of the rainy season and rainfall in the Brazilian Amazon Basin. J Climate 14: 4308-4318

Manzi AO, Planton S (1996) A simulation of Amazonian land use using a GCM calibrated with ABRACOS and ARME data. In: Gash JHC, Nobre CA, Roberts JM, Victoria RL (eds) Amazonian deforestation and climate. Chichester: John Wiley \& Sons, pp 505-529

Marengo JA, Liebmann B, Kousky VE, Filizola NP, Wainer IC (2001) Onset and end of the rainy season in the Brazilian Amazon Basin. J Climate 14: 833-852

Nepstad DC, Carvalho CR, Davidson EA, Jipp PH, Lefebvre PA, Negreiros GH, da Silva ED, Stone TA, Trumbore SE, Vieira S (1994) The role of deep roots in the hydrological and carbon cycles of Amazonian forests and pastures. Nature 372: 666-669

Nepstad DC, Moutinho P, Dias-Filho MB, Davidson E, Cardinot G, Markewitz D, Figueiredo R, Vianna N, Chambers J, Ray D, Guerreiros JB, Lefebvre P, Sternberg L, Moreira M, Barros L, Ishida FY, Tohlver I, Belk E, Kalif K, Schwalbe K (2002) The effects of partially 
throughfall exclusion on canopy processes, aboveground production, and biogeochemistry of an Amazon forest. J Geophys Res 107: D20, 8085, doi: 10.1029/ 2001JD000360

Nobre CA, Sellers PJ, Shukla J (1991) Amazon land use and regional climate change. J Climate 4: 4,957-4,988

Nobre CA, Fisch G, Rocha HR, Lyra RFF, Rocha EP, Costa ACL, Ubarana VN (1996) Observations of the atmospheric boundary layer in Rondônia. In: Gash JHC, Nobre CA, Roberts JM, Victoria RL (eds) Amazonian deforestation and climate. Chichester: John Wiley \& Sons, pp 413-424

Pierrehumbert RT (1995) Thermostats, radiator fins, and the local runaway greenhouse. J Atmos Sci 52: 1784-1806

Polcher J (1995) Sensitivity of tropical convection to land surface processes. J Atmos Sci 52: 3143-3161

Rind D, Rossow WB (1984) The effects of physical processes on the Hadley circulation. J Atmos Sci 41: 479-507

Salati E, Dall'Olid A, Matsui E, Gat JR (1979) Recycling of water in the Amazon basin: An isotopic study. Water Resour Res 15: 1250-1258

Salati E, Vose PB (1984) Amazon Basin: A system in equilibrium. Science 225: 129-138

Silva Dias MAF, Regnier P (1996) Simulation of mesoscale circulations in a deforested area of Rondônia in the dry season. In: Gash JHC, Nobre CA, Roberts JM, Victoria RL (eds) Amazonian deforestation and climate. Chichester: John Wiley \& Sons, pp 531-547

Souza JRS, Pinheiro FMA, Araujo RLC, Pinheiro HS, Hodnett MG (1996) Temperature and moisture profiles in soil beneath forest and pasture areas in eastern Amazon. In: Gash JHC, Nobre CA, Roberts JM, Victoria RL (eds) Amazonian deforestation and climate. Chichester: John Wiley \& Sons, pp 57-77

Wallace JM (1992) Effect of deep convection on the regulation of tropical sea surface temperature. Nature 357: 230-231

Wang H, Fu R (2002) Cross-equatorial flow and seasonal cycle of precipitation over South America. J Climate 15: 1591-1608

Webster PJ, Magaña VO, Palmer TN, Shukla J, Tomas RA, Yanai M, Yasunari T (1998) Monsoons: processes, predictability, and the prospects for prediction. J Geophys Res 103(C7): 14,451-14,510

Werth D, Avissar R (2002) The local and global effects of Amazon deforestation. J Geophys Res 107(D20): 8087, DOI: $10.1029 / 2001 J D 000717$

Williams ER, Rennó N (1993) An analysis of the conditional instability of the tropical atmosphere. Mon Wea Rev 121: 21-36

Williamson GB, Laurance WF, Oliveira AA, Delamonica P, Gascon C, Lovejoy TE, Pohl L (2000) Amazon tree mortality during the 1997 El Niño drought. Conserv Biol 14: $1538-1542$

Authors' address: Dr. Rong Fu (e-mail: fu@eas.gatech. edu), Dr. Wenghong Li, School of Earth and Atmospheric Sciences, Georgia Institute of Technology, Ford ES\&T Bldg., 311 Ferst Dr., Atlanta, GA 30332, USA. 